\title{
Language Use in Deaf Children With Early-Signing Versus Late-Signing Deaf Parents
}

\author{
Beyza Sümer ${ }^{1 *}$ and Aslı Özyürek $k^{2,3}$ \\ ${ }^{1}$ Department of Linguistics, Amsterdam Center for Language and Communication (ACLC), University of Amsterdam, Amsterdam, \\ Netherlands, ${ }^{2}$ Center for Language Studies, Radboud University, Nijmegen, Netherlands, ${ }^{3}$ Donders Institute for Brain, Cognition \\ and Behavior, Radboud University, Nijmegen, Netherlands
}

\section{OPEN ACCESS}

Edited by: Erin Wilkinson,

University of New Mexico,

United States

Reviewed by:

Chloe Marshall,

University College London,

United Kingdom

Matthew L. Hall,

Temple University, United States

*Correspondence:

Beyza Sümer

b.sumer@uva.n

Specialty section:

This article was submitted to

Language Sciences,

a section of the journal

Frontiers in Communication

Received: 29 October 2021

Accepted: 27 December 2021

Published: 21 January 2022

Citation:

Sümer B and Özyürek A (2022) Language Use in Deaf Children With Early-Signing Versus Late-Signing

Deaf Parents.

Front. Commun. 6:804900. doi: $10.3389 /$ fcomm.2021.804900
Previous research has shown that spatial language is sensitive to the effects of delayed language exposure. Locative encodings of late-signing deaf adults varied from those of early-signing deaf adults in the preferred types of linguistic forms. In the current study, we investigated whether such differences would be found in spatial language use of deaf children with deaf parents who are either early or late signers of Turkish Sign Language (TiD). We analyzed locative encodings elicited from these two groups of deaf children for the use of different linguistic forms and the types of classifier handshapes. Our findings revealed differences between these two groups of deaf children in their preferred types of linguistic forms, which showed parallels to differences between late versus early deaf adult signers as reported by earlier studies. Deaf children in the current study, however, were similar to each other in the type of classifier handshapes that they used in their classifier constructions. Our findings have implications for expanding current knowledge on to what extent variation in language input (i.e., from early vs. late deaf signers) is reflected in children's productions as well as the role of linguistic input on language development in general.

Keywords: sign language acquisition, late sign language acquisition, early sign language acquisition, spatial language, language production

\section{INTRODUCTION}

Unlike hearing children who most of the time have early input from their speaking parents, only a small proportion of deaf children (5-10\%) receive language input in a sign language mainly from their deaf parents (thus becoming early signers of their language), while the rest does not receive linguistic input accessible to them mainly because they have non-signing hearing parents (Mitchell and Karchmer, 2004). Thus, they may start learning a sign language later in their lives (e.g., at 6 years of age or later, thus becoming late signers), usually after meeting other deaf people at school or in other social environments such as deaf clubs/cafes ${ }^{1}$. A crucial body of research has shown effects of delayed language exposure on language skills of these late signers compared to early signers (e.g.,

\footnotetext{
${ }^{1}$ Please note that we here refer to the timing of receiving sign language input (early vs. late). As suggested by Henner and Robinson (2021) as well as Koulidobrova and Pichler (2021, this special issue), these signers had initial communication systems before starting to acquire a sign language, thus their sign language can be considered as their second language.
} 
Newport, 1988; Newpot 1990; Karadöller et al., 2017; Mayberry and Kluender, 2018; Karadöller et al., 2021).

In our paper, we are interested in the fact that these late signers may become language models for deaf children. Research conducted with deaf signers usually make a distinction between those with deaf parents versus hearing parents. However, as mentioned above, deaf parents themselves might have received sign language input later in their lives. Thus, their language skills might vary from deaf parents with early sign language exposure. We do not know much about whether and how language use in deaf children with late-signing deaf parents and deaf children with early-signing deaf parents parallels to the patterns observed in deaf adults who are early-versus late-signers.

Previous work with a single deaf child acquiring American Sign Language (ASL) from his deaf parents who are late signers of ASL reported that his signing skills went beyond the language input despite the inconsistent forms (i.e., forms not observed in language productions of deaf signers who acquired ASL since birth) it contained (Ross and Newport, 1996; Singleton and Newport, 2004). However, this is based on a single case study. Furthermore, this finding seems to be in contrast with the research on spoken languages suggesting robust effects of input quality (e.g., syntactic complexity; diversity of vocabulary) on language development (e.g., Rowe, 2012; Hoff and Core, 2013; Jones and Rowland, 2017) as well as the evidence suggesting a facilitating role of language input from native speakers for language development compared to that of nonnative speakers (i.e., speakers using their L2 with their children) (Hoff, 2006 for a comprehensive review). To examine these effects for sign language acquisition, we compared language productions of two groups of deaf children with early-signing (acquired sign language since birth) versus late-signing deaf parents (acquired sign language at around adolescence, Newport, 1988). To facilitate the flow of reading, we will refer to deaf children with early-signing deaf parents as DCES (Deaf Children of Early Signers) and deaf children with late-signing deaf parents as DCLS (Deaf Children of Late Signers). Studying language patterns in such a cohort of deaf signing children expands the previous research since it mainly drew its conclusions based on a single case study in ASL or from spoken language development only.

For spoken language development, the effects of non-native language input have been studied mainly in bilingual language development. Compared to native-speaking adults, non-nativespeaking adults' vocabulary and morpho-syntax are likely to be less diverse and less sophisticated, and they are not as phonologically accurate as native speakers (e.g., Core and Hoff, 2014). Thus, the quality of linguistic input that children receive varies greatly depending on the adult language models, which seems to have robust effects on language development. For example, vocabulary use differences and the variation in the phonological accuracy among mothers who are non-native speakers of English are strong predictors of their children's vocabulary development (Core and Hoff, 2014). Furthermore, in a study with Spanish-English bilingual children, Place and Hoff (2011) found that the proportion of children's English input from native speakers was a stronger predictor of their vocabulary and grammar development in English compared to the amount of English input (from both native and non-native speakers) that they receive. In another study with Spanish-English bilingual children, Hoff et al. (2014) reported that English use at home facilitated development of English for these children more when one of the parents was a native speaker of English compared to the cases in which both parents were non-native speakers of English, but still used English at home. In a recent study, Unsworth et al. (2019) found that the degree of nonnativeness in the input is a better predictor of bilingual children's language skills compared to the proportion of native input that they receive or having a native speaker parent or not.

It is important to note however that the caregivers described in many of these previous studies have relatively low proficiency in their later-acquired language compared to their first-acquired language. However, this is not the case with late-signing deaf adults since they are highly proficient in the language that they learnt later in their lives. Furthermore, for these late-signing deaf parents, their sign language can be considered as their second language since they were already using an initial communication system before acquiring a sign language (Henner and Robinson, 2021; Koulidobrova and Pichler, 2021). Thus, it might be more meaningful to consider speakers who are highly proficient in their later-acquired language (i.e., reversed dominance bilinguals) for comparison. Although there is a growing body of research on their language use and processing (e.g., Declerck et al., 2020; Gollan et al., 2020), research examining the effects of their language input on their children's language development is scarce. In one recent study, Stoehr et al. (2019) asked whether language development in Dutch-German bilingual pre-schoolers has been influenced by the language input from their sequential bilingual mothers, who acquired Dutch in their adulthood, and have been using it dominantly in their daily lives. In their study, they focused on the productions of voice onset time (VOT), for which mothers' productions were still non-native in Dutch despite being highly proficient in this language and using it on a daily basis, and also became different than those in German, which is their first language. In this study, they found that their bilingual children differed from their monolingual peers in both languages in the timing of voice onsets. Thus, these findings suggest that bilingual children's language productions were influenced by their mother's highly proficient but still nonnative speech patterns.

Non-native input, as defined in these studies, refers to the use of a second language (sometimes together with a native first language with code-switching/mixing) by parents. However, it is also possible that monolingual parents' language productions might include errors while interacting with their children. Earlier work examining how monolingually developing children deal with errors in input has shown that they regularize them when these errors are at low levels of complexity, and according to the dominant pattern in language input in general (Kam and Newport, 2005; Kam and Chang, 2009). Thus, it seems that monolingual children can track structural relations in the language input that they receive despite a certain degree of variation that exists in the input that they receive (Gonzáles et al., 2015). Children's age has also been shown to be significant 
in this process. In a recent study, Austin et al. (2021) found that the younger the (speaking) children are, the more regular their language productions are despite the inconsistent forms in their input. When children are at around 7-8 years of age, their ability to regularize language input starts to diminish. Moreover, children in their study could acquire low frequency forms as long as they are used in a consistent fashion, thus showing a stronger role of consistency than that of frequency of linguistic patterns in language input to children.

Considering the findings of the above-mentioned studies, there seems to be conflicting evidence on to what extent and how language patterns used by language models shape language patterns produced by children. Studies conducted with bilingual children who receive non-native input from their parents suggest language proficiency of the parents to be a strong predictor for children's language abilities (e.g., Hoff et al., 2014; Stoehr et al., 2019; Unsworth et al., 2019). On the other hand, studies with monolingual children, who can be exposed to errors and variations in their parents' speech, indicate that these children's language productions do not reflect such forms, thus suggesting that these children can regularize them in their own language use (Kam and Newport, 2005; Kam and Chang, 2009; Gonzáles et al., 2015; Austin et al., 2021). However, it is not clear how frequent and persistent these forms are in parents' input to their children. Thus, it is possible that they might happen at such a low frequency that children may be ignoring them. Furthermore, De Bree et al. (2015) showed that bilingual children, but not monolingual children, could learn novel language patterns when presented with input with variations, and concluded that bilingual children are better at detecting regularities in language input compared to monolingual children. Therefore, children's ability to deal with variation in their language input might be related to bilingualism (De Bree et al., 2015) or complexity of linguistic forms (Kam and Newport, 2005; Kam and Chang, 2009) or frequency of such variations in the input (Gonzales et al., 2015; Austin et al., 2021).

Research on sign language acquisition presents us a possible avenue to approach these issues in a novel way because of the heterogenous profile of language acquirers, which is mainly the result of different ages of sign language acquisition by deaf signers. A crucial body of research has shown the effects of delayed language exposure on language skills of late signers compared to early signers (see Mayberry and Kluender, 2018 for a review). In a series of studies, Newport (1988, 1990) compared early-signing deaf adults to late-signing deaf adults on several syntactic and morphological language production tasks. She found performance differences between these groups in different aspects of morphologically complex constructions. To be specific, she concluded that early exposure to sign language is of utmost importance to master morphologically complex verbs of motion and location, and that late input has long-lasting effects on their mastery even in adulthood. In two recent studies, Karadöller et al. (2017; 2021) compared descriptions of spatial configurations of objects by late-signing deaf children (aged between $7 ; 3-10$; 9) and late-signing deaf adults to the agematched early-signing deaf users of Turkish Sign Language (TID). Their results revealed that in describing locative relations between objects (e.g., pen left to paper), early signers mainly used morphologically complex classifier predicates, in which the location of the hands encodes the location of the referents, while the handshape encodes referent type by classifying it in terms of certain semantic features such as size and shape (Supalla, 1982; Emmorey, 2002; Zwitserlood et al., 2012; Sümer et al., 2014; Perniss et al., 2015; Sümer, 2015). In Figure 1A below, a TID signer first introduces the lexical signs for Ground (paper) and Figure (pen) and uses a classifier construction in which the flat surface of her right hand is the classifier handshape for the paper and the index finger of her left hand is the classifier handshape for the pen. The position of her hands in signing space encodes the spatial relation as shown in the stimulus picture. Late signers used these forms less frequently than early signers. They rather preferred morphologically less complex linguistic forms such as pointing to space to indicate relative locations between objects as shown in Figure 1C, in which another TID signer points to the location of the Figure (cat) with respect to the Ground (boat) encoded by a classifier handshape (her left hand). Please note that the signer first introduced the lexical signs for Ground and Figure objects in her spatial description.

In TID, it is also possible to use lexical signs (i.e., relational lexemes) that mean LEFT or RIGHT to encode these spatial relations (Sümer et al., 2014; Sümer, 2015; Karadöller et al., 2017; Karadöller et al., 2021). Relational lexemes encode spatial relationships between entities but not the information about the shape of the specific entities themselves. Thus, they are semantically less specific and iconic to the size and shape of the referents than classifier predicates are since they only exhibit the relationship between any two objects regardless of their size and shape. Therefore, as relational lexemes do not require classifier handshapes and locations in space, they can be considered to be morphologically less complex. In these forms, TID signers tap onto the upper part of their left or right arms or at the back of their left or right hands. In Figure 1B below, after introducing the lexical signs for Ground (paper) and Figure (pen), a TID signer uses the relational lexeme in which she taps her left arm to encode left in her locative description. Please note that these forms can be used as the mere locative strategy in spatial descriptions or combined with classifier constructions or other locative strategies such as pointing (Sümer et al., 2014; Sümer, 2015). In their study, Karadöller et al. (2017; 2021) found similarities in how early and late signers of TİD use these forms.

As shown by above-mentioned studies, early (with deaf parents) and late signers (with hearing parents) differ in their locative encodings in terms of the language forms that they employ. We do not know much if and to what extent these differences will be observed in the locative encodings of deaf children with such early-versus late-signing deaf parents. In a previous study, Lu et al. (2016) compared early lexical sign productions of deaf children with deaf parents to deaf children with hearing parents with level one proficiency in British Sign Language (BSL). So, these hearing parents, for whom sign language was a second language, provided sign language input to their deaf children-albeit with forms that differed from deaf 


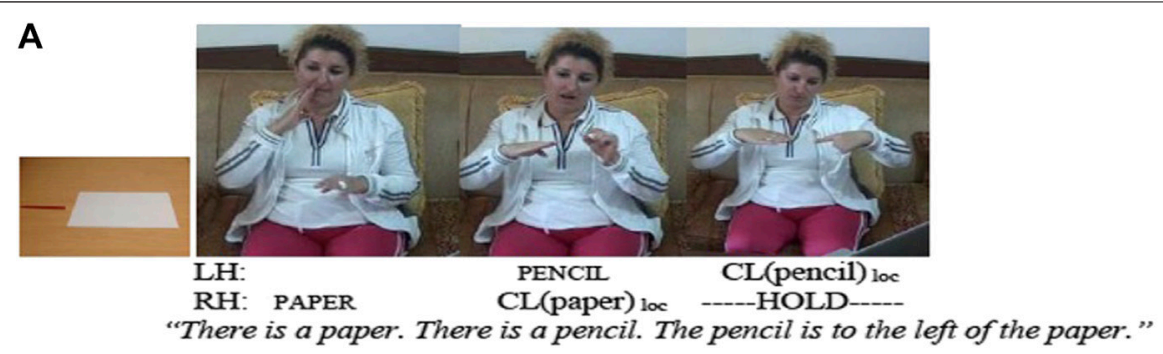

B
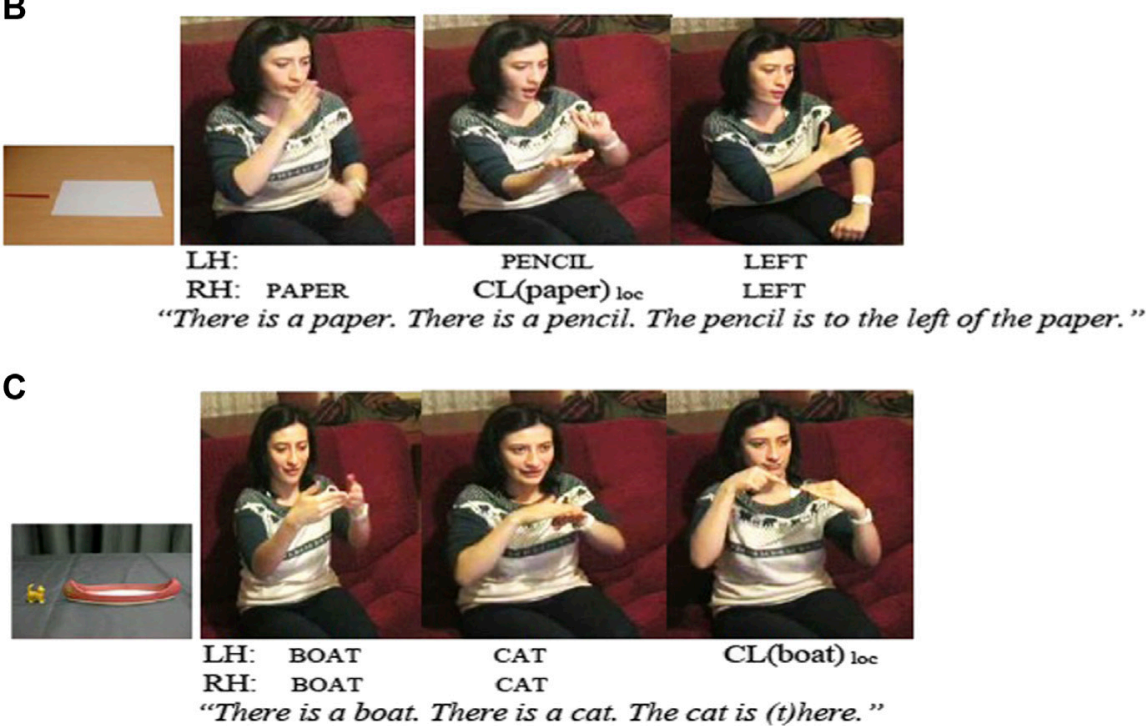

FIGURE 1 | Different locative forms used to describe object locations by TiD signers.

early signers of BSL. It is also important to note that these hearing parents reported using English with their deaf children, thus providing bimodal bilingual language input. The study found that deaf children with hearing parents knew fewer lexical signs and made more errors in using correct handshapes in these lexical signs that they produced than deaf children with deaf parents. However, it is not clear how their output compared to adult patterns in terms of accuracy and complexity. There is also one case study with an ASL-acquiring deaf boy (Simon) whose deaf parents were late ASL signers (Ross and Newport, 1996; Singleton and Newport, 2004). In this study, covering between 2; 6-9; 1 year of age, researchers looked into his motion event encodings, and compared them to those elicited from his late-signing deaf parents as well as his deaf peers with early-signing deaf parents. As a result, they found his classifier constructions in encoding motion events to be more regular than those of his parents since they were similar to those produced by early signers of ASL in terms of indicating movement of the referents and use of signing space in these forms.

However, certain aspects of Simon's productions differed from those of early signers of ASL. For example, his choice of classifier handshapes in classifier predicates was not similar to that of early signers. Indeed, differences in classifier handshape choice were also observed between his parents and early-signing deaf adults. It seems that Simon's output in using classifier handshapes parallels to these differences between his parents and early signers of ASL. It is also important to note that the difference in the use of classifier handshapes was observed for encoding the central objects (i.e., moving object), but not the secondary ones (i.e., relative to which central objects move) in his data. However, these findings come from only one case study, thus it is not clear if these findings can be generalized to other signing children who receive language input that is characterised by variations.

In the current study, we investigated how language productions of deaf children with late-signing deaf parents compared to those from deaf children with early-signing deaf parents by collecting data from a large cohort of sign language acquiring deaf children. Here, we focused on the domain of spatial language, more specifically locative encodings, for which recent studies have shown differences in the choice of linguistic forms between early and late signers of TiD (Karadöller et al., 2017; Karadöller et al., 2021). Considering the previous research, we entertained the following predictions: if DCLS are similar to DCES, it would suggest that differences reported in encoding locative relations between early and late 
adult signers are not reflected in the language productions of these children. Therefore, despite the possible variation that these children might receive in their language input, their developmental track in learning to encode spatial relations will be similar to each other (Ross and Newport, 1996; Singleton and Newport, 2004; Kam and Newport, 2005; Kam and Chang, 2009; Gonzales et al., 2015; Austin et al., 2021). It is also possible that DCLS will be using classifier predicates less often than DCES, thus being parallel to the differences observed in early versus late adult signers. Thus, the differences observed in the language productions of these children can be explained by and reflect the linguistic input that they receive from the language models (e.g., Hoff, 2006; Place and Hoff, 2011; Rowe, 2012; Hoff and Core, 2013; Core and Hoff, 2014; Jones and Rowland, 2017). Finally, it is also possible to see differences in deaf children's outputs for different aspects of locative encodings such as differences for the use of classifier handshapes (Ross and Newport, 1996; Singleton and Newport, 2004), but not for the frequency of using different locative forms.

The findings of our study will contribute to current understanding on children's ability to deal with variation in adults' use of language by providing evidence from a unique population of deaf children with deaf parents with varying ages of sign language exposure, that has never been studied systematically before. In addition, the present study is about monolingual language development, thus controlling for a possible effect of bilingualism-unlike previous studies with speaking children ${ }^{2}$. Our study is also unique in examining the language input by parents who are highly proficient in a language that they have acquired later in their lives, which has been largely unexplored for spoken language development (but Stoehr et al., 2019). Furthermore, it presents a broader perspective by focusing on different aspects of locative encodings such as types of linguistic forms and classifier handshapes rather than by focusing on only classifier constructions or phonological handshapes. It also presents data from a larger group of deaf children with deaf parents, thus expanding the previous research by Ross and Newport (1996) and Singleton and Newport (2004) and providing more data on this topic. Finally, sign language studies so far grouped deaf signers with deaf parents as native signers without considering the differences in language performance of their deaf parents, which might be modulating sign language development in various ways. This study aims to shed light on whether and how such a differentiation among so-called native signers, considering differences in their input, can be meaningful in sign language acquisition research as well as contributing data on the role of language input on language development in children in general.

${ }^{2}$ In our study, we consider deaf children to be monolingual signers of Turkish Sign Language (TID) since their teachers and parents reported that they have low reading, writing and oral language proficiency in Turkish or any other spoken language.
TABLE 1 | The number (N) of participants as well as the mean $(M)$ and the standard deviation (SD) of their ages.

\begin{tabular}{lccc}
\hline & Number & $\mathbf{M}_{\text {AGE }}$ & SD $_{\text {AGE }}$ \\
\hline Early-signing deaf adults & 8 & 27 & 8.7 \\
Late-signing deaf adults & 8 & 41.25 & 6.5 \\
Deaf children with early signing parents & 8 & 8.27 & 1.15 \\
Deaf children with late signing parents & 8 & 8.09 & 0.92 \\
\hline
\end{tabular}

\section{MATERIALS AND METHODS}

\section{Participants}

As mentioned earlier, early signers consist of a very small proportion of a deaf population (Mitchell and Karchmer, 2004), which makes it a challenging task to find enough participants for this study. It was even a further challenge since the current study divided deaf children with deaf parents into two groups. For this reason, we analyzed data previously collected for two different projects, which entertained related research questions. Thus, the data used for this paper have been published before in papers with a different research focus, namely the comparison of spatial language development between early signing deaf children and speaking children (e.g., Sümer, 2015) and effects of delayed sign language exposure on learning to encode various spatial relations (Karadöller et al., 2017; 2021).

Deaf children in the current study were split into two groups: DCES (mean age $=8.27$ ) and DCLS (mean age $=8.09$ ) with eight children in each group. We also analyzed locative encodings elicited from a group of early-signing deaf adults (also with earlysigning deaf parents) as well as a group of late adult signers of TİD, who acquired TID after 7 years of age ( $n=8$ in each group) for the classifier handshape analysis (Table 1 for their demographic information) since we lack previous studies on the differences between early and late signers for the use of classifier handshapes in locative encodings in TID.

All participants reside in Istanbul, Turkey. All deaf children in this study attend a school for the deaf. It is important to note that TİD was not systematically taught at the schools for the deaf, and thus was not part of the curriculum at the time of data collection. Furthermore, deaf children and adults learned very little Turkish at school. Adult participants reported themselves to be profoundly deaf and unable to understand spoken Turkish as well as not being proficient in reading and writing in Turkish.

\section{Stimuli}

To collect language production data, we used a picture description task, which showed slight variations in format between the two projects (Figure 2 above). Please note that the differences in stimuli did not meaningfully contribute to our findings as revealed by the statistical models used for the data analysis.

In this task, participants were asked to describe a target picture (indicated with a red frame or a black arrow) displayed together with three other pictures (non-targets) in a picture set. In all of these pictures, one object (Figure) was situated in relation to another object (Ground). All the target pictures analyzed for the current study showed objects located on the lateral axis (e.g., pen 

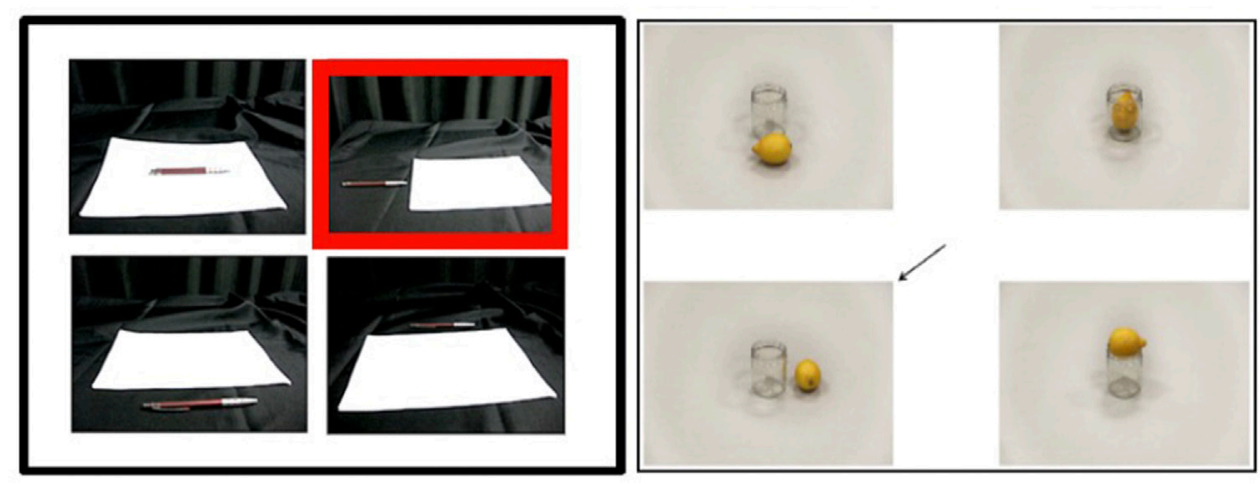

FIGURE 2 | Example of the displays used in the current study. Differences in their format (e.g., background, indication of the target pictures to be described) are because they were used in two different, but related, projects. The stimuli on the left were originally developed by Dr Jennie Pyers (Wellesley College, The United States).

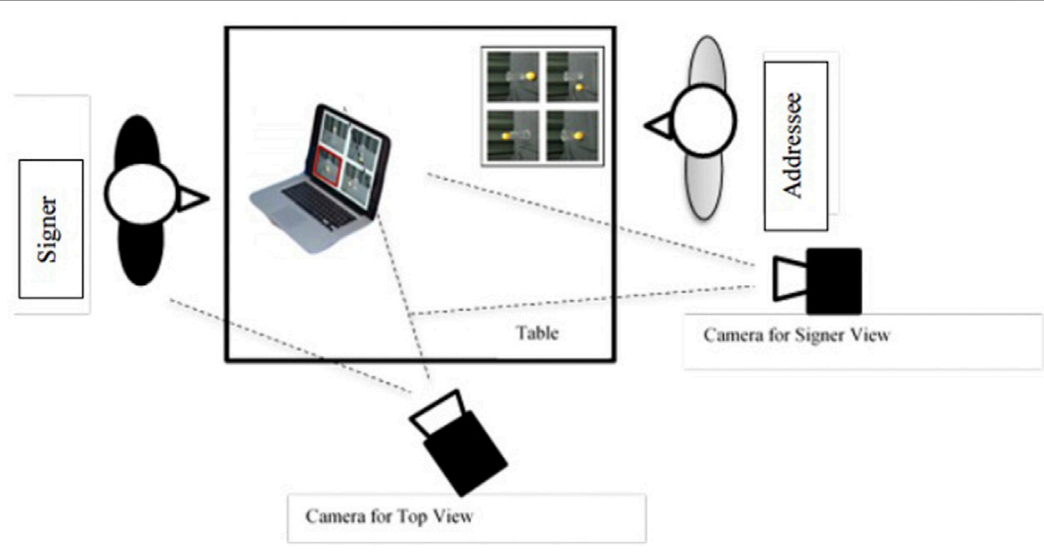

FIGURE 3 | Data collection set-up.

left to a paper). In the non-target pictures, the location of the objects varies such as sagittal axis (pen in front of paper), containment (lemon in jar), or support (pen on paper). In total, there were 118 picture sets, out of which 34 picture sets were analyzed, and the rest functioned as fillers. We chose left and right as the focus of the current study because we previously found systematic differences between early- and late signing deaf adults in encoding them, but not for in and on type of spatial encodings (Karadöller et al., 2017; 2021). Furthermore, it is not yet known whether and how early and late signing deaf adults differ in encoding front/behind in TİD, and therefore there is no baseline for comparing our findings with.

\section{Procedure}

In data collection sessions, signers were asked to sit opposite the addressee, who was a deaf confederate. There was a laptop located on a table between them, and the table was below the waist of the participants so that their hands could easily be seen (Figure 3). To collect data, the participants were shown sets of four pictures and asked to describe the target picture with the red frame/arrow to the addressee who had the same picture set (but without any red frames/arrows and pictures in a scrambled order) in a booklet in front of them. The task of the addressee was to choose the picture described by the signer. The participants were asked to describe the target picture. They were never asked questions such as "Where is X?" before they began their descriptions since such questions might have invoked a description of the location of that object without a full locative description. Addressee did not give any feedback on whether the descriptions were correct or not. In cases where the participants did not express the spatial relations, addressee only asked for the location of the Figure item using the lexical sign of WHERE in TID and the lexical sign of the Figure item in the target picture. Thus, addressee feedback did not provide any linguistic strategies to locate the Figure item in relation to the Ground item. All participants' descriptions were recorded by two cameras from different angles so that both a front and a top view were available, providing as much information as possible on locations, movement directions and sign forms, which facilitated the coding of the data considerably. However, since data collection sessions took place in different 
home and classroom environments, recording set-ups and camera angles showed some variation in different data collection sessions.

\section{Data Coding and Analysis}

The picture descriptions were annotated, coded, and checked by a deaf signer of TID and two hearing researchers with knowledge of TID. The annotations were done in ELAN, a free annotation tool (http://tla.mpi.nl/tools/tla-tools/elan/) for multimedia resources, developed by the Language Archive Group at the Max Planck Institute for Psycholinguistics in Nijmegen, Netherlands (Wittenburg et al., 2006).

Picture descriptions in which children encoded a correct spatial relation (i.e., left, right) between Figure and Ground were coded for 1) the type of linguistic forms used to indicate the spatial relation and 2) classifier handshapes used to encode the location of the Figure object with respect to the Ground object. For the first point, we compared two groups of deaf children with each other only since we already knew preferred patterns from both early and late adult signers of TİD from previous work (Karadöller et al., 2017; Karadöller et al., 2021). Thus, we wanted to see if similar patterns reported in this previous work were also observed in DCES versus DCLS in the current study. Please note that we could not compare these deaf children with their deaf parents in interaction because we lack data. However, we also think that, in such a comparison, it would be difficult to understand the possible effects of childdirected signing, in which parents tend to simplify linguistic forms for their deaf children even when these children would be around 8 years of age (Perniss et al., 2017; Ortega et al., 2017). It would then be difficult to understand the differences between two groups of deaf parents if they modify and/or simplify input in describing locative relations. For the second point, we coded data from a group of early-signing adults (with early-signing deaf parents) as well as a group of adult late signers (with nonsigning hearing parents, thus exposed to sign language, for example, at around 6 years of age or later) for their preferences in the use of classifier handshapes in their locative constructions since we did not have previous knowledge on these patterns from these groups in TID. In this analysis, we also focused on the classifier handshapes for Figure only following Ross and Newport (1996) and Singleton and Newport (2004), who reported errors in classifier handshapes for the location of Figure (primary) objects, but not for the Ground (secondary) objects.

The coding and analysis of our data for the linguistic strategies used in the correct spatial encodings in which the location of the Figure item was mentioned in relation to the Ground item revealed three main categories: 1) classifier constructions, 2) relational lexemes, and 3) other forms such as pointing. In Figure 4, a deaf child (with early-signing deaf parents) is describing the location of the soap with respect to the jar. After introducing the lexical signs for the jar and the soap, he uses a classifier construction in which his left handshape represents the round shape of the jar, and the shape of his right hand refers to the flat surface of the soap. The location of his hands in signing space reflects how the soap is located in relation with the jar in the picture. In Figure 5, another deaf child (with early-signing deaf parents) is describing a picture that displays an apple to the right of a box. After mentioning the lexical signs for the entities in the picture, he uses a lexical sign that means RIGHT in TID. In Figure 6, a deaf child (with late-signing deaf parents) is encoding the location of the wristwatch with respect to the cup. In her description, lexical signs for the entities are followed by the use of an index finger pointing directed towards the left side of the signing space.

Next, we focused on the descriptions in which signers used a classifier predicate to encode the spatial relation between the Figure and the Ground. Here we focused on only the use of the classifier handshape to encode the location of the Figure since earlier studies (Ross and Newport, 1996; Singleton and Newport, 2004) reported a difference between Simon and his deaf peers of early-signing deaf parents in the use of classifier handshapes for the primary objects (i.e., Figure), but not for the secondary ones (i.e., Ground). Please note that in this analysis, we compared not only two groups of deaf children with each other, but also compared them to a group of adult early and late signers of TID, as opposed to two previous analyses, since we lack data on the adult-like patterns of using classifier handshapes in locative constructions in TİD. Here we used the classifier handshape inventory for TİD (Kubus, 2012). For each spatial display, we listed the classifier handshapes for Figure objects as preferred by adult early signers. As shown in Figure 7 below, in our data, for example, it emerged that early signers of TID used 8-handshape (or V-hooked) to localize the Figure (horse) in signing space (third still, left hand). Thus, other handshapes used for the same Figure by deaf adult late signers as well as deaf children were considered to differ than the patterns observed for the early signers (Figure 8).

\section{RESULTS}

Data presented in this section were analyzed using generalized binominal linear-mixed effects modelling (glmer) with random intercepts for Participants. All models were fit with the lme4 package (version 1.1.21; Bates et al., 2015) in R (R Core Team, 2019).

As the first step, we checked if two groups of deaf children differed in how frequently they encoded a correct spatial relation (i.e., left, right) out of all picture descriptions in which they expressed Figure, Ground, and a locative form $(n=205)$. Please note that we included all the descriptions with a left or right encoding, thus did not consider possible viewpoint differences (i.e., encoding right for a picture that displays objects in a left configuration). It is also important to note that we took out non-responses or responses that were missing Figure, Ground, and/or spatial encoding $(n=13)$ since they could have happened as a result of the factors not related to the lack of ability to encode spatial relations (e.g., not seeing the objects or spatial relation clearly). For example, In Figure 9 below, a deaf child (with early signing deaf parents) is producing the lexical signs for the cup and the banana without further encoding the spatial relation between them. Also, in Figure 10, 


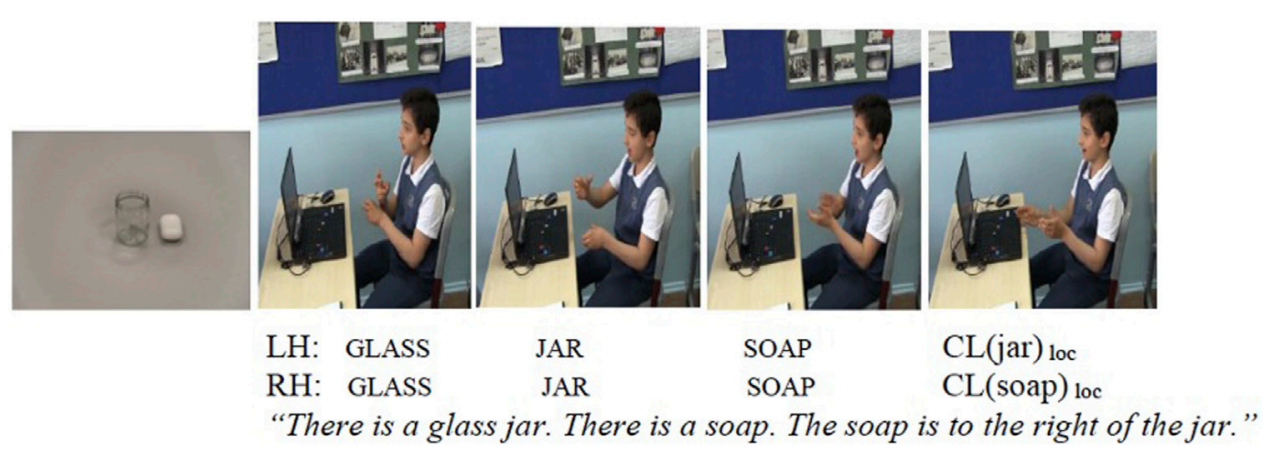

FIGURE 4 | Encoding the spatial relation between Figure and Ground in classifier predicates in TiD.

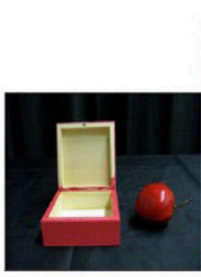

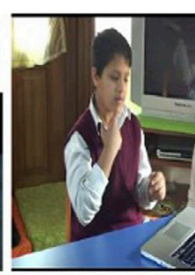
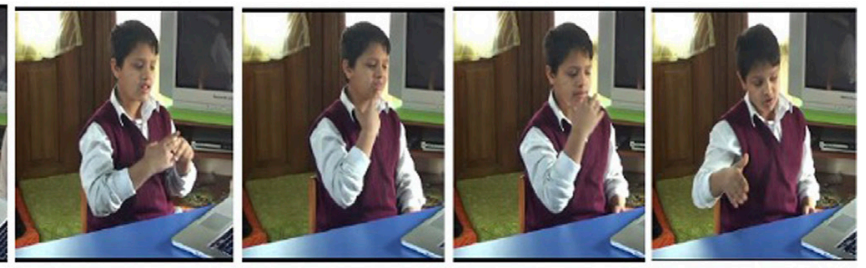

LH:

WOOD

RH: RED

WOOD

RED

RIGHT

"There is a red wood. There is an apple. The apple is to the right."

FIGURE 5 | Encoding the spatial relation between Figure and Ground by using a relational lexeme in TiD.

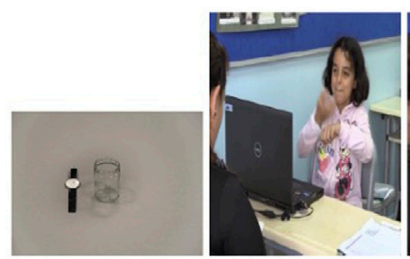

LH: GLASS

RH: GLASS

"There is a glass cup. There is a watch. The watch is here."
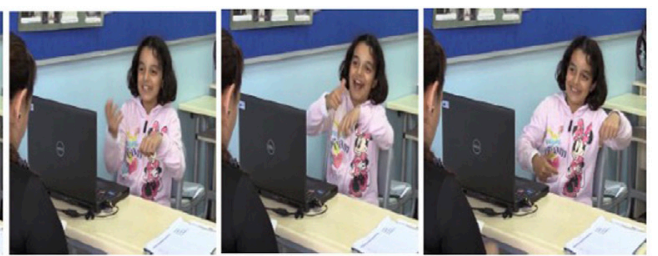

IX

FIGURE 6 | Encoding the spatial relation between Figure and Ground by using an index finger pointing in TiD.

another deaf child (with early signing deaf parents), encodes the lexical sign for the apple, and then shows its location without mentioning the box, which makes the description too vague to understand the location of the apple. Thus, descriptions like these were not considered to encode a (correct) spatial relation between the objects. We also checked this decision with our deaf research assistants and informants, who advised similarly, and indicated that the descriptions were not correct/informative enough in TiD.

The comparison of the picture descriptions with a correct spatial encoding $(M=0.98, S E=0.01$ for DCES, and $M=0.94, S E$
$=0.02$ for DCLS) to those with incorrect ones (e.g., front, on) showed no differences between two groups of deaf children $(\beta=$ $1.28, S E=0.83, z=1.55, p>0.5)$.

\section{Types of Linguistic Forms in Spatial Encodings}

In order to understand whether DCES and DCLS differ in their preferred linguistic forms to encode spatial relations, we focused on the picture descriptions with correct spatial encoding (left, right). To this end, we used separate glmer 


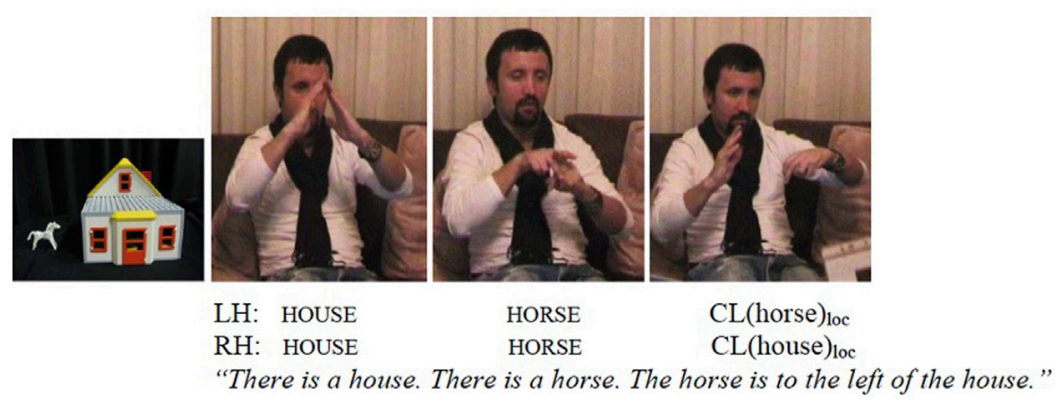

FIGURE 7 | Use of a classifier predicate with a classifier handshape as preferred by an early signer of TiD.

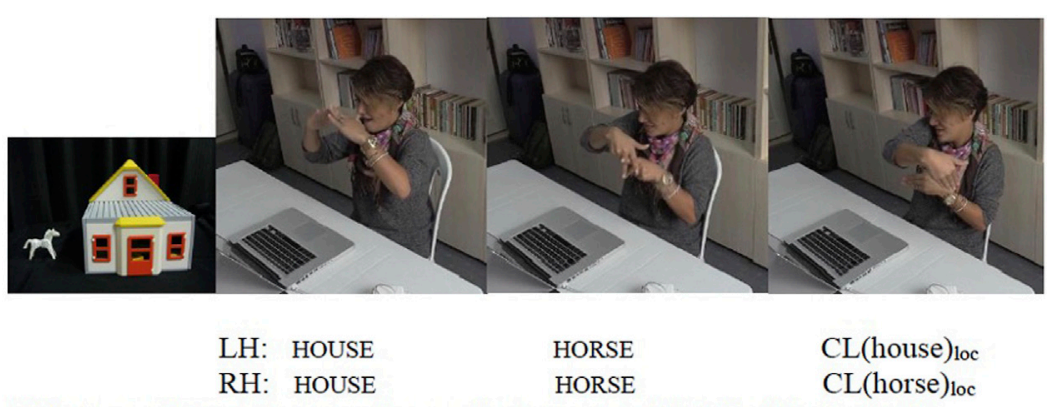

"There is a house. There is a horse. The horse is to the left of the house."

FIGURE 8 | Use of a classifier predicate with a classifier handshape which is not observed in the patterns found for early signers of TiD.

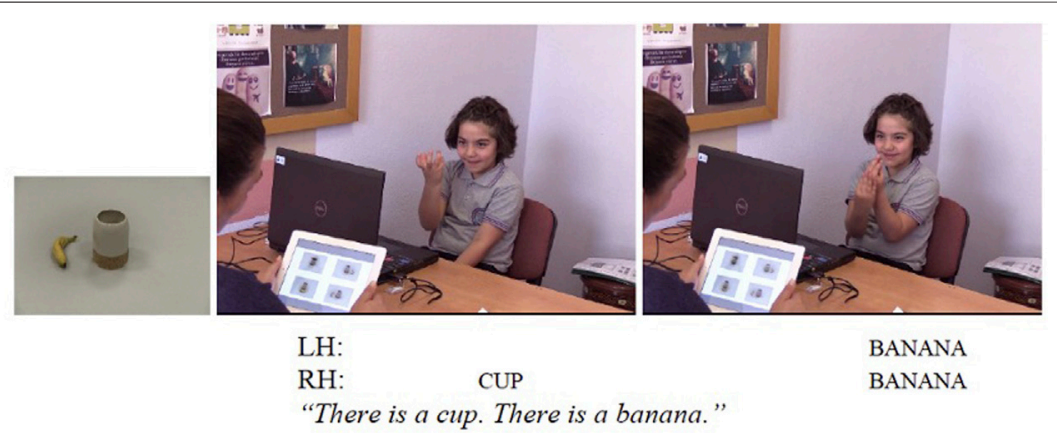

FIGURE 9 | Picture description that does not include any encoding of a spatial relation between objects.

models to test the fixed effect of Group (DCES, DCLS), coded with numeric contrasts, on the use of each linguistic form (Classifier Constructions, Relational Lexemes, Other), which was coded as the binary dependent variable $(0=\mathrm{No}, 1=\mathrm{Yes})$. It is also important to note that in some of the descriptions, participants used more than one linguistic strategy to describe the spatial relation in the target picture. For example, one description could include both a classifier construction followed or preceded by a relational lexeme. These cases were counted for the presence of both categories. Consequently, the results presented in this part include all the strategies for a single description and thus allow us to investigate each linguistic strategy with separate models, which is also similar to the statistical models used in the study by Karadöller et al. (2021).

As a result of these analyses, we found main effects of Group (DCLS, DCES) on the use of Classifier Constructions $(p<0.05)$ and Other forms $(p<0.001)$ : DCES preferred classifier constructions more frequently than DCLS (Figure 11; Table 2). For the use of linguistic forms from the Other category, we saw a reverse pattern, in which DCLS used them more often than DCES (Figure 12; Table 3). We did not observe any effects of Group for the use of relational lexemes $(\beta=-0.27$, $S E=1.21, z=-0.23, p>0.5$ ). 


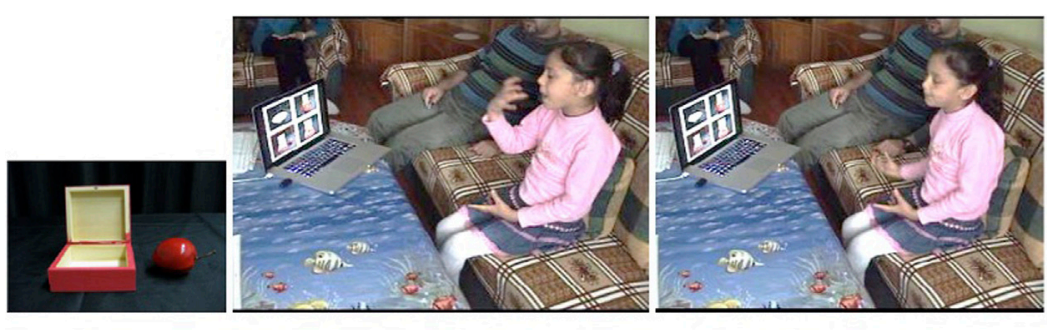

LH:

RH: APPLE CL(apple) loc

"There is an apple. The apple is here."

FIGURE 10 | Picture description that does not include the mention of the Ground object (box).

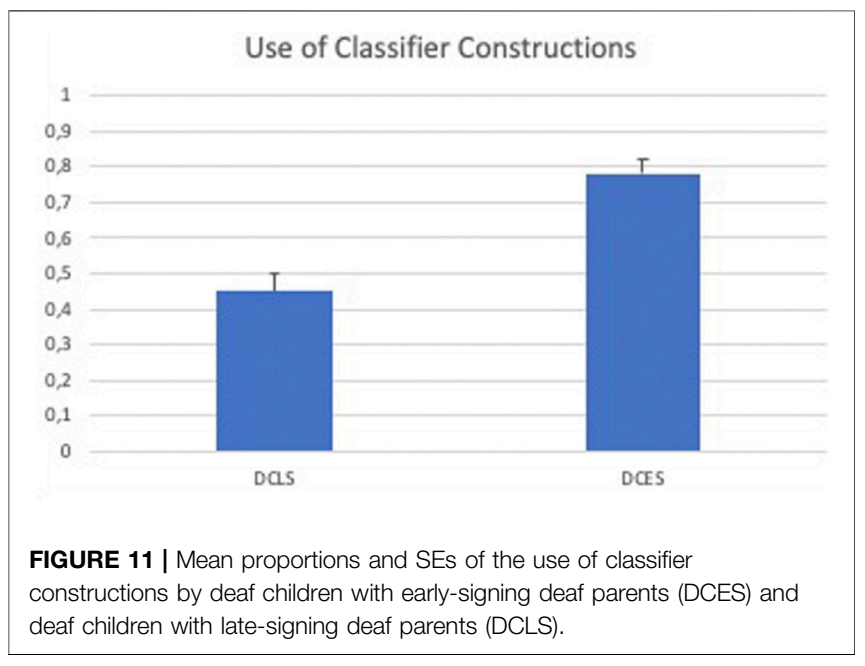

TABLE 2 | Fixed effect estimates from the glmer model for frequency of classifier constructions use.

\begin{tabular}{lcccc}
\hline Fixed effect & - & - & - & - \\
\hline- & $\beta$ & $S E$ & $z$ & $p$ value \\
(Intercept) & 0.48 & 0.26 & 1.84 & 0.06 \\
Group & 1.27 & 0.53 & 2.42 & $<0.02^{*}$
\end{tabular}

Significance codes: ${ }^{*} 0.05,{ }^{* *} 0.01,{ }^{* *} 0.001$. Formula in R: Using Classifier Constructions $\sim$ Group + (1 | Participants).

\section{Types of Classifier Handshapes in Classifier Constructions}

We further investigated the use of different classifier handshapes in picture descriptions where signers used a classifier construction. Please note that in the following analyses, we only focused on the classifier handshapes used to represent the location of the Figure object, as in line with earlier studies by Ross and Newport (1996), and Singleton and Newport (2004). Here we were interested in understanding whether the preferences for different classifier handshapes differed between: 1) two groups of children (DCES vs. DCLS); 2) two groups of adults (early vs. late), 3) DCES and early-signing adults, and 4) DCLS and late-signing adults.

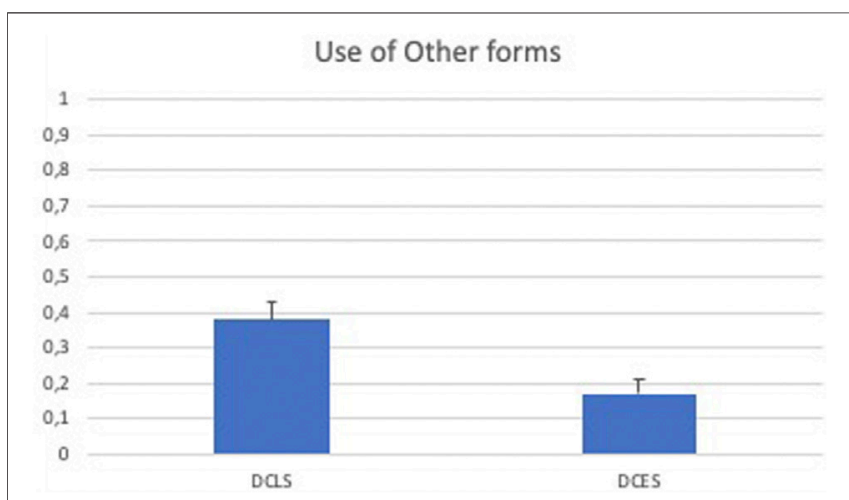

FIGURE 12 | Mean proportions and SEs of the use of language forms Other than classifier constructions and relational lexemes (e.g., pointing signs) by deaf children with early-signing deaf parents (DCES) and deaf children with late-signing deaf parents (DCLS).

TABLE 3 | Fixed effect estimates from the glmer model for frequency of use of other forms.

\begin{tabular}{lcccc} 
Fixed effect & - & - & - & - \\
\hline- & $\beta$ & $S E$ & $z$ & $p$ value \\
(Intercept) $_{\text {Group }}$ & -0.99 & 0.21 & -4.76 & $<0.001^{\star \star \star}$ \\
\hline
\end{tabular}

Significance codes: ${ }^{*} 0.05,{ }^{* *} 0.01,{ }^{* *} 0.001$. Formula in $\mathrm{R}$ : Using Other forms $\sim$ Group $+(1$ | Participants).

To understand if the two groups of deaf children differed in their use of classifier handshapes in their locative expressions, we tested the fixed effect of Group (DCLS, DCES), coded with numeric contrasts, on the binary dependent variable of classifier handshape choices $(0=$ Classifier handshapes different than those of earlysigning adults, 1 = Classifier handshapes as also used by earlysigning adults). This analysis did not reveal a difference between the two groups (Figure 13; Table 4).

We further examined if late-signing adults were similar to earlysigning adults in their choice of classifier handshapes. Thus, we tested the fixed effect of Language Status (Early-signing, Late-signing), coded with numeric contrasts, on the binary dependent variable of 


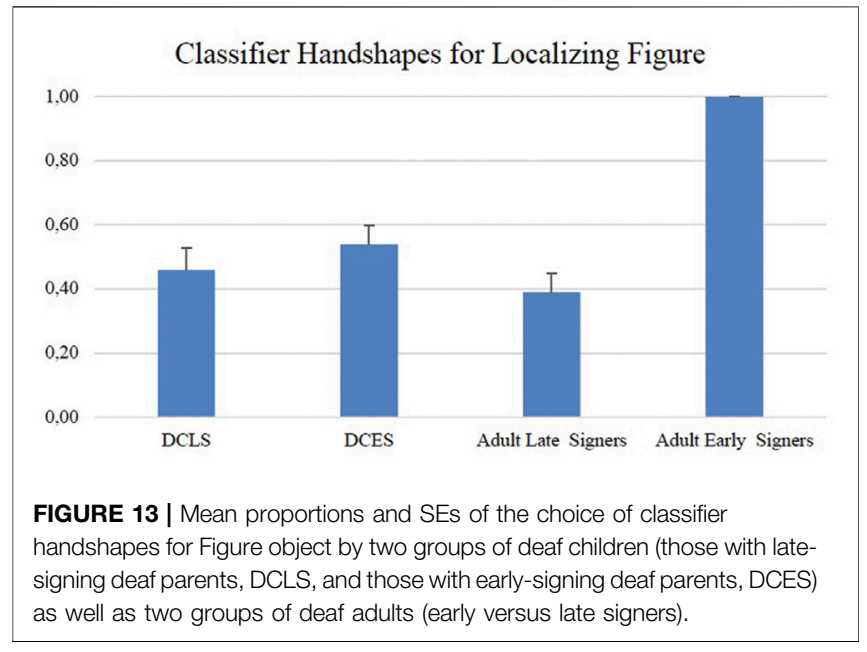

TABLE 4 | Fixed effect estimates from the glmer model for frequency of using classifier handshapes by deaf children in each group.

\begin{tabular}{lcccc}
\hline Fixed effect & - & - & - & - \\
\hline- & $\beta$ & $S E$ & $z$ & $p$ value \\
(Intercept) & 0.03 & 0.17 & 0.17 & 0.87 \\
Group & -0.33 & 0.34 & -0.97 & 0.33
\end{tabular}

Significance codes: ${ }^{*} 0.05,{ }^{* *} 0.01,{ }^{* * *} 0.001$. Formula in R: Using classifier handshapes Group + (1| Participants).

TABLE 5 | Fixed effect estimates from the glmer model for frequency of using classifier handshapes by deaf adults.

\begin{tabular}{lcccc}
\hline Fixed effect & - & - & - & - \\
\hline- & $\beta$ & $S E$ & $z$ & $p$ value \\
(Intercept) & 18.45 & 181.2 & 0.102 & 0.92 \\
Language StatuS Early vs Late & -37.81 & 362.04 & -0.104 & 0.92 \\
\hline
\end{tabular}

Significance codes: ${ }^{*} 0.05,{ }^{* *} 0.01,{ }^{* *} 0.001$. Formula in R: Using classifier handshapes Language Status + (1| Participants).

classifier handshape choices $(0=$ Classifier handshapes different than those of early-signing adults, 1 = Classifier handshapes as used by early-signing adults). We did not find any statistical differences in their choice of classifier handshapes (Figure 13; Table 5).

In order to check to what extent deaf children were similar to deaf adults in their classifier handshape preferences, we compared DCES to early-signing adults (Table 6) and DCLS to late-signing adults (Table 7). We did not observe any differences between these groups (Figure 13).

\section{DISCUSSION}

In this study, we examined locative encodings of deaf children with early-signing versus late-signing deaf parents. Considering the previous research showing substantial differences in linguistic encoding of space (more specifically for left-right encodings) between early and late signers of TID (Karadöller et al., 2017; 2021), it is possible that these two groups of deaf children could also differ in their spatial descriptions. We explored this possibility,
TABLE 6 | Fixed effect estimates from the glmer model for frequency of using classifier handshapes by DCES and early-signing deaf adults.

\begin{tabular}{lcccc} 
Fixed effect & - & - & - & - \\
\hline- & $\beta$ & $S E$ & $z$ & $p$ value \\
(Intercept) & 17.77 & 159.92 & 0.111 & 0.91 \\
Age $_{\text {DCES vs Early-signing deaf adults }}$ & 35.15 & 319.84 & 0.110 & 0.91
\end{tabular}

Significance codes: ${ }^{*} 0.05,{ }^{* *} 0.01,{ }^{* *} 0.001$. Formula in R: Using classifier handshapes Age + (1 | Participants).

TABLE 7 | Fixed effect estimates from the glmer model for frequency of using classifier handshapes by DCLS and late-signing deaf adults.

\begin{tabular}{lcccc} 
Fixed effect & - & - & - & - \\
\hline- & $\beta$ & $S E$ & $z$ & $p$ value \\
(Intercept) & -0.30 & 0.19 & -1.63 & 0.10 \\
Age $_{\text {DCLS vs Late-signing deaf adults }}$ & -0.31 & 0.36 & -0.87 & 0.38
\end{tabular}

Significance codes: ${ }^{*} 0.05,{ }^{* *} 0.01,{ }^{* * *} 0.001$. Formula in R: Using classifier handshapes Age $+(1 \mid$ Participants).

previously tackled by Ross and Newport (1996) and Singleton and Newport (2004) for sign language acquisition, by focusing on a larger cohort of deaf children, who were divided into two groups depending on whether their deaf parents were early signers of TID or not. We compared these two groups of deaf children in how frequently they used linguistic forms (classifier constructions, relational lexemes, other forms such as pointing) in locative constructions as well as how frequently they used a classifier handshape as preferred by early-signing adults. We found differences between two groups of children in their preferences of using different linguistic forms in their locative encodings in ways parallel to the differences in early and late signing adults as reported in previous research. Such a difference, on the other hand, was not observed for the use of classifier handshapes.

\section{Types of Linguistic Forms Used in Locative Encodings}

Previous studies showed different language production patterns between early and late adult signers both for the expression of motion events (Newport, 1988; Newport, 1990) and the locative expressions (Karadöller et al., 2017; Karadöller et al., 2021). In our study, DCLS differed from DCES in choosing classifier constructions less often. They, instead, preferred forms such as pointing to the location of the Figure object with respect to the Ground object. This pattern is quite similar to that of reported for late adult signers of TİD (Karadöller et al., 2017; Karadöller et al., 2021). Our study, thus, provides further evidence for such a variation in even deaf children with deaf parents. Thus, the effects of delayed sign language exposure may not be immediate to deaf signers with hearing parents, but to their deaf children, as well.

Although we did not compare these deaf children with their deaf parents due to the possible confounding effect of child-directed signing, the variation in using locative forms in these two groups of deaf children might still suggest corroborating support for the role of language input (e.g., Rowe, 2012; Hoff and Core, 2013; Jones and Rowland, 2017) on language development by showing that 
differences observed between early and late deaf adult signers were also found in deaf children with deaf parents who are either early or late signers. This finding seems to stand in contrast with the evidence suggested by the earlier studies for speaking children's ability to regularize input when exposed to inconsistent patterns (Kam and Newport, 2005; Kam and Chang, 2009; De Bree et al., 2017; Austin et al., 2021). In our study, we also attested their finding with data from deaf children who kept the variation that they were exposed to in their language productions.

However, the characterization of input differs in our study compared to the studies with speaking children and parents. In our case, some of the language forms produced by late-signing adults and DCLS in encoding left and right type of spatial relations (e.g., pointing) can be considered to be well-formed and accepted despite being less preferred by early-signing adults and DCES. Therefore, one can think that DCLS might have been simply aligning with the patterns in their linguistic input rather than failing to regularize it since these forms are not inconsistent as defined by the research with speaking populations. The difference observed between two groups of deaf children makes it difficult to distinguish these two views. If DCLS would have been found to be similar to DCES in their preferences of locative forms, then linguistic alignment between these children and their language models would be a less likely interpretation. This would then suggest a weaker role of language input on shaping language development. However, the differences between early- and late-signing adults were also found between two groups of children, which suggests language learning processes in children could be influenced by language models and input in their environment, and one mechanism that allows this could be linguistic alignment in language productions of children and adults.

Finally, language productions of DCLS in our study diverged from those of ASL-acquiring deaf child (Simon) studied by Ross and Newport (1996) and Singleton and Newport (2004). However, in that study, Simon could surpass his language models for movement/location morpheme, but not for classifier handshape morpheme. In our study, we did not focus on individual morphemes, but first took a general perspective to see if there are differences in the types of locative forms preferred by them. We do not know if and what type of other language forms were used by Simon and his deaf parents in their motion event descriptions. One significant difference between Simon and DCLS in our study was that Simon did not attend a school for the deaf, thus his linguistic input was limited to his deaf parents. DCLS, on the other hand, were exposed to sign language input from various sources such as their deaf peers at school. In this case, one might assume less alignment between children's output and their deaf parents' input due to more variation that these children were exposed to. However, it is likely that these children were exposed to sign language input mostly form late-signing deaf peers (with hearing parents), which might have reinforced their patterns even further.

Regarding the use of relational lexemes to encode object locations, our results did not reveal a difference between these two groups of deaf children. This is also similar to the previous research showing no differences in using these forms by early and late adult signers of TİD (Karadöller et al., 2017; Karadöller et al.,
2021). It seems that these deaf children have an understanding of left and right since they could use these terms correctly. However, when it comes to using morphologically complex constructions such as classifier constructions, DCLS used them less frequently than DCES. Relational lexemes can be considered to be morphologically less complex compared to classifier constructions since handshapes in these forms do not denote any size and/or shape information about the referents: they are frozen lexical items used for these spatial relations regardless of the type of the objects. Previous studies on the differences in language productions of early versus late signers consistently report more frequent use of frozen lexical verbs (rather than verbs of motion) in describing motion events (Newport, 1988; Newport, 1990). Thus, in our study, we also observed a similar pattern for the locative expressions in deaf children whose deaf parents differ in their age of TID acquisition. It is also important to note that these relational lexemes in TID can also be bodyanchored in which signers tap their left arms or back of their left hands to encode left and their right arms or back of their right hands for right. Previously, Sümer (2015) and Sümer et al. (2014) found an early acquisition of these forms (around 4 years of age) by deaf children acquiring TID from their deaf parents and suggested a facilitating role of body in their production. In the current study, simple morphological structure of the relational lexemes as well as involvement of body in their production might have helped DCLS become similar to DCES in the use of these locative forms.

\section{Types of Classifier Handshapes in Classifier Constructions}

Our final analysis, which was on the use of classifier handshapes, did not reveal any differences between two groups of deaf children. Moreover, they were also similar to early-signing adults in their choice of classifier handshapes in their locative descriptions. Considering the fact that there was no difference between earlyand late-signing adults as revealed by the current study, it is not surprising to see that two groups of deaf children were similar to each other in this respect. It seems that although DCLS differed from DCES in their choice of locative forms in describing spatial relations (classifier predicates versus other forms such as pointing), when they used classifier constructions, their classifier handshapes used to refer to entities (Figure object more specifically) were similar.

Lack of difference between two groups of deaf children in their use of classifier handshapes in locative expressions seems to be in contrast with what was found for Simon by Ross and Newport (1996) and Singleton and Newport (2004). In their study, classifier handshape was the only parameter for which Simon could not surpass his language models, i.e., his deaf parents. Furthermore, previous studies report that late signers do not catch up with early signers in their choice of classifier handshapes, and handshape being the most susceptible to the effects of delayed language exposure (Newport, 1988; Newport, 1990; Singleton and Newport, 2004). In our study, handshape in classifier constructions seems to be resilient to the possible differences in 
language acquisition of these two groups of deaf children. This might be due to the nature of locative spatial relations as opposed to motion events, which include more components (Figure, Ground, Motion, Path, Manner) (Talmy, 1985; Engberg-Pedersen, 1993; Taub and Galvan, 2001; Cuxac and Sallandre, 2007). Thus, effects of late language exposure or exposure to variation in input might become evident when signers are engaged in producing syntactically and semantically more complex utterances. Syntactic complexity was also observed to be a factor contributing to the differences in language productions of early versus late signers. For example, Newport (1990) reports no differences among three groups of ASL signers (native, early, and late) in their acquisition of basic word order. Similarly, for adolescents acquiring a sign language as a first language, Ramirez et al. (2013) found the use of relatively short and non-complex utterances, and the acquisition of declaratives earlier than more syntactically complex utterances such as Wh-questions, although they might still differ in the strategies (e.g., event knowledge rather than basic word order) that they use to comprehend sentences (Cheng and Mayberry, 2021). Similarly, Cheng and Mayberry (2019) provide further evidence for the resilience of simple syntactic structures to the effects of delayed language exposure.

\section{CONCLUSION}

In our study, we have presented evidence for both similarities and differences in the language use of two groups of deaf children with deaf parents, who were first exposed to a sign language at different ages (since birth or at later ages). Differences previously reported for early-versus late-signing adults in their locative form preferences were observed between these two groups of deaf children as well. However, these children did not differ in the handshapes they used in classifier constructions to encode object locations. We would like to highlight that all the locative forms produced by the deaf children in our study were acceptable forms in TID although some might be preferred less often than the others. Thus, our findings do not suggest any detrimental effects of language input by deaf parents who are late signers themselves. We rather show that language productions of children are influenced by the language patterns that they are exposed to in their immediate environment.

\section{REFERENCES}

Austin, A. C., Schuler, K. D., Furlong, S., and Newport, E. L. (2021). Learning a Language from Inconsistent Input: Regularization in Child and Adult Learners. Lang. Learn. Develop., 1-29. doi:10.1080/15475441.2021.1954927

Bates, D., Kliegl, R., Vasishth, S., and Baayen, H. (2015). Parsimonious Mixed Models. arXiv. arXiv preprint arXiv:1506.04967.

Cheng, Q., and Mayberry, R. I. (2021). When Event Knowledge Overrides Word Order in Sentence Comprehension: Learning a First Language after Childhood. Dev. Sci. 24 (5), e13073. doi:10.1111/desc.13073

Cheng, Q., and Mayberry, R. I. (2019). Acquiring a First Language in Adolescence: the Case of Basic Word Order in American Sign Language. J. Child. Lang. 46 (2), 214-240. doi:10.1017/s0305000918000417

Core, C., and Hoff, E. (2014). Phonetic Properties of L2 Child Directed Speech and Effects on Child Language Development [Poster Presentation]. Boston, MA: Boston University Conference on Language Development.

\section{DATA AVAILABILITY STATEMENT}

The datasets presented in this study can be found in online repositories. The names of the repository/repositories and accession number(s) can be found below: archive.mpi.nl.

\section{ETHICS STATEMENT}

The studies involving human participants were reviewed and approved by the Radboud University. Written informed consent to participate in this study was provided by the participants' legal guardian/next of kin. Written informed consent was obtained from the individual (s), and minor (s)' legal guardian/next of kin, for the publication of any potentially identifiable images or data included in this article.

\section{AUTHOR CONTRIBUTIONS}

All authors have made a substantial, direct and intellectual contribution to the work, and approved it for publication.

\section{FUNDING}

This research is supported by the NWO-VICI Grant and European Research Council (ERC) Starting Grant awarded to the second author.

\section{ACKNOWLEDGMENTS}

We thank our deaf assistants Sevinc Yücealtay Akın, Şule Kibar, Yusuf Ermez and hearing assistant Hukümran Sümer for their help in collecting, annotating, and coding data. Some of the stimuli in the study were originally developed by Jennie Pyers (Wellesley College, The United States), and we thank her for sharing these materials with us. The authors are very grateful to Nick Wood $\dagger$ and Jeroen Geerts for helping us with processing the video data.

Cuxac, C., and Sallandre, M. A. (2007). "Iconicity and Arbitrariness in French Sign Language: Highly Iconic Structures, Degenerated Iconicity and Diagrammatic Iconicity," in Verbal and Signed Languages: Comparing Structures, Constructs and Methodologies. Editors E. Pizzuto, P. Pietrandrea, and R. Simone (Berlin: Mouton de Gruyter), 13-33.

De Bree, E., Verhagen, J., Kerkhoff, A., Doedens, W., and Unsworth, S. (2017). Language Learning from Inconsistent Input: Bilingual and Monolingual Toddlers Compared. Inf. Child. Dev. 26, e1996. doi:10.1002/icd.1996

Declerck, M., Kleinman, D., and Gollan, T. H. (2020). Which Bilinguals Reverse Language Dominance and Why? Cognition 204, 104384. doi:10.1016/ j.cognition.2020.104384

Emmorey, K. (2002). Language, Cognition, and the Brain: Insights from Sign Language Research. Mahwah, NJ: Lawrence Erlbaum Associates.

Engberg-Pedersen, E. (1993). Space in Danish Sign Language: The Semantics and the Morphosyntax of the Use of Space in a Visual Language. Hamburg: Signum Press. 
Ferjan Ramirez, N., Leonard, M. K., Torres, C., Hatrak, M., Halgren, E., and Mayberry, R. I. (2013). Neural Language Processing in Adolescent FirstLanguage Learners. Cereb. Cortex 24, 2772-2783. doi:10.1093/cercor/bht137

Gollan, T. H., Li, C., Stasenko, A., and Salmon, D. P. (2020). Intact Reversed Language-Dominance but Exaggerated Cognate Effects in reading Aloud of Language Switches in Bilingual Alzheimer's Disease. Neuropsychology 34 (1), 88-106. doi:10.1037/neu0000592

Gonzáles, K., Gerken, L. A., and Gómez, R. L. (2015). Does Hearing Two Dialects at Different Times Help Infants Learn Dialect Specific Rules? Cognition 140, 60-71. doi:10.1016/j.cognition.2015.03.015

Henner, J., and Robinson, O. (2021). Unsettling Languages, Unruly Bodyminds: Imaging a Crip Linguistics. Available at: https://psyarxiv.com/7bzaw (Accessed December 21, 2021).

Hoff, E., and Core, C. (2013). Input and Language Development in Bilingually Developing Children. Semin. Speech Lang. 34 (4), 215-226. doi:10.1055/s-0033-1353448

Hoff, E. (2006). How Social Contexts Support and Shape Language Development 弥. Develop. Rev. 26, 55-88. doi:10.1016/j.dr.2005.11.002

Hoff, E., Rumiche, R., Burridge, A., Ribot, K. M., and Welsh, S. N. (2014). Expressive Vocabulary Development in Children from Bilingual and Monolingual Homes: A Longitudinal Study from Two to Four Years. Early Child. Res. Q. 29, 433-444. doi:10.1016/j.ecresq.2014.04.012

Jones, G., and Rowland, C. F. (2017). Diversity Not Quantity in Caregiver Speech: Using Computational Modeling to Isolate the Effects of the Quantity and the Diversity of the Input on Vocabulary Growth. Cogn. Psychol. 98, 1-21. doi:10.1016/j.cogpsych.2017.07.002

Kam, C. L. H., and Chang, A. (2009). Investigating the Cause of Language Regularization in Adults: Memory Constraints or Learning Effects? J. Exp. Psychol. Learn. Mem. Cogn. 35 (3), 815-821. doi:10.1037/a0015097

Kam, C. L. H., and Newport, E. L. (2005). Regularizing Unpredictable Variation: The Roles of Adult and Child Learners in Language Formation and Change. Lang. Learn. Develop. 1 (2), 151-195. doi:10.1080/15475441.2005.9684215

Karadöller, D. Z., Sümer, B., and Özyürek, A. (2021). Effects and Non-effects of Late Language Exposure on Spatial Language Development: Evidence from Deaf Adults and Children. Lang. Learn. Develop. 17 (1), 1-25. doi:10.1080/ 15475441.2020.1823846

Karadöller, D. Z., Sümer, B., and Özyürek, A. "Effects of Delayed Language Exposure on Spatial Language Acquisition by Signing Children and Adults," in Proceedings of the 39th Annual Conference of the Cognitive Science Society (CogSci 2017), London UK, July 2017. Editors G. Gunzelmann, A. Howes, T. Tenbrink, and E. Davelaar (Austin, TX: Cognitive Science Society), 2372-2376.

Koulidobrova, E., and Pichler, C. (2021). Cripping the "Delay": MultilingualismRelated Consequences of Re-labeling Language Deprivation Systems. Front. Commun. 6, 751457. doi:10.3389/fcomm.2021.751457

Kubus, O. (2012). An Analysis of Turksish Sign Language (TID) Phonology and Morphology. master's thesis (Ankara, Turkey: ODTU).

Lu, J., Jones, A., and Morgan, G. (2016). Early Sign Phonological Development in Deaf Children: Age of Acquisition and Quality of Input Matter. J. Child Lang. 43, 537-552. doi:10.1017/S0305000915000835

Mayberry, R. I., and Kluender, R. (2018). Rethinking the Critical Period for Language: New Insights into an Old Question from American Sign Language. Bilingualism 21 (5), 886-905. doi:10.1017/s1366728917000724

Mitchell, R. E., and Karchmer, M. A. (2004). When Parents Are Deaf versus Hard of Hearing: Patterns of Sign Use and School Placement of Deaf and Hard-OfHearing Children. J. Deaf Stud. Deaf Edu. 9 (2), 133-152. doi:10.1093/deafed/ enh017

Newport, E. L. (1988). Constraints on Learning and Their Role in Language Acquisition: Studies of the Acquisition of American Sign Language. Lang. Sci. 10, 147-172. doi:10.1016/0388-0001(88)90010-1

Newport, E. L. (1990). Maturational Constraints on Language Learning. Cogn. Sci. 14, 11-28. doi:10.1207/s15516709cog1401_2

Perniss, P., Lu, J., Morgan, G., and Vigliocco, G. (2017). Mapping Language to the World: The Role of Iconicity in the Sign Language Input. Develop. Sci. 21, 1-23. ISSN 1363-755X. doi:10.1111/desc.12551

Perniss, P., Zwitserlood, I., and Özyürek, A. (2015). Does Space Structure Spatial Language?: A Comparison of Spatial Expression across Sign Languages. Language 91 (3), 611-641. doi:10.1353/lan.2015.0041
Place, S., and Hoff, E. (2011). Properties of Dual Language Exposure that Influence 2-Year-Olds' Bilingual Proficiency. Child. Develop. 82, 1834-1849. doi:10.1111/ j.1467-8624.2011.01660.x

R Core Team (2019). R: A Language and Environment for Statistical Computing. Vienna, Austria: R Foundation for Statistical Computing. Available at: https:// www.R-project.org/.

Ross, D. S., and Newport, E. L. (1996). “The Development of Language from Nonnative Linguistic Input," in Proceedings of the 20th Annual Boston University Conference on Language Development. Vol. 2. Editors A. Stringfellow, D. Cahana-Amitay, E. Hughes, and A. Zukowski (Somerville, MA: Cascadilla Press).

Rowe, M. L. (2012). A Longitudinal Investigation of the Role of Quantity and Quality of Child-Directed Speech in Vocabulary Development. Child. Develop. 83, 1762-1774. doi:10.1111/j.1467-8624.2012.01805.x

Singleton, J. L., and Newport, E. L. (2004). When Learners Surpass Their Models: The Acquisition of American Sign Language from Inconsistent Input. Cogn. Psychol. 49 (4), 370-407. doi:10.1016/j.cogpsych.2004.05.001

Stoehr, A., Benders, T., van Hell, J. G., and Fikkert, P. (2019). Bilingual Preschoolers' Speech Is Associated with Non-native Maternal Language Input. Lang. Learn. Develop. 15 (1), 75-100. doi:10.1080/ 15475441.2018.1533473

Sümer, B., Perniss, P., Zwitserlood, I., and Özyürek, A. (2014). "Learning to Express "Left-Right" \& "Front-Behind" in a Sign versus Spoken Language," in Proceedings of the 36th Annual Meeting of the Cognitive Science Society (CogSci 2014). Editors P. Bello, M. Guarini, M. McShane, and B. Scassellati (Austin, Tx: Cognitive Science Society).

Supalla, T. R. (1982). Structure and Acquisition of Verbs of Motion and Location in American Sign Language. dissertation (San Diego, California: UCSD).

Sümer, B. (2015). Acquisition of Spatial Language by Signing and Speaking Children: A Comparison of Turkish Sign Language (TID) and Turkish. dissertation (Nijmegen, Netherlands: Radboud University Nijmegen).

Talmy, L. (1985). "Lexicalization Patterns: Semantic Structure in Lexical Forms," in Language Typology and Syntactic Description. Editor T. Shopen (Cambridge, United Kingdom: Cambridge University Press).

Taub, S. F., and Galvan, D. (2001). Patterns of Conceptual Encoding in ASL Motion Descriptions. Sign Lang. Stud. 1 (2), 175-200. doi:10.1353/ sls.2001.0006

Unsworth, S., Brouwer, S., de Bree, E., and Verhagen, J. (2019). Predicting Bilingual Preschoolers' Patterns of Language Development: Degree of Non-native Input Matters. Appl. Psycholinguistics 40 (5), 1189-1219. doi:10.1017/ S0142716419000225

Wittenburg, P., Brugman, H., Russel, A., Klassmann, A., and Sloetjes, H. "ELAN: A Professional Framework for Multimodality Research [Conference Presentation]," in 5th international conference on Language Resources and Evaluation (LREC 2006), Genoa-Italy, May 2006.

Zwitserlood, I., Perniss, P., and Özyürek, A. (2012). An Empirical Investigation of Expression of Multiple Entities in Turkish Sign Language (TID): Considering the Effects of Modality. Lingua 122, 1636-1667. doi:10.1016/ j.lingua.2012.08.010

Conflict of Interest: The authors declare that the research was conducted in the absence of any commercial or financial relationships that could be construed as a potential conflict of interest.

Publisher's Note: All claims expressed in this article are solely those of the authors and do not necessarily represent those of their affiliated organizations, or those of the publisher, the editors and the reviewers. Any product that may be evaluated in this article, or claim that may be made by its manufacturer, is not guaranteed or endorsed by the publisher.

Copyright $\odot 2022$ Sümer and Özyürek. This is an open-access article distributed under the terms of the Creative Commons Attribution License (CC BY). The use, distribution or reproduction in other forums is permitted, provided the original author(s) and the copyright owner(s) are credited and that the original publication in this journal is cited, in accordance with accepted academic practice. No use, distribution or reproduction is permitted which does not comply with these terms. 